\title{
Modeling Carbon Sequestration over the Large-Scale Amazon Basin, Aided by Satellite Observations. Part I: Wet- and Dry-Season Surface Radiation Budget Flux and Precipitation Variability Based on GOES Retrievals
}

\author{
Jiujing Gu, ${ }^{*}$ Eric A. Smith, ${ }^{+}$Harry J. Cooper, ${ }^{*}$ Andrew Grose,* Guosheng Liu,* James D. Merritt,* \\ MaArten J. Waterloo,” Alessandro C. De Araújo, @ Antonio D. Nobre, ${ }^{\circledR}$ Antonio O. Manzi,\& \\ Jose Marengo, \& Paulo J. De Oliveira, \& Celso von Randow, \& John Norman,** \\ AND Pedro Silva Dias ${ }^{+}+$ \\ *Department of Meteorology, The Florida State University, Tallahassee, Florida \\ ${ }^{+}$NASA Goddard Space Flight Center, Greenbelt, Maryland \\ \#Vrije Universiteit Amsterdam, Amsterdam, Netherlands \\ @ Instituto Nacional de Pesquisas da Amazônia, Manaus, Brazil \\ ${ }^{2}$ CPTEC/INPE, Cachoeira Paulista, Brazil \\ **Department of Soil Sciences, University of Wisconsin-Madison, Madison, Wisconsin \\ ${ }^{+}{ }^{+}$Department of Atmospheric Sciences, University of São Paulo, São Paulo, Brazil
}

(Manuscript received 12 March 2002, in final form 5 September 2003)

\begin{abstract}
In this first part of a two-part investigation, large-scale Geostationary Operational Environmental Satellite (GOES) analyses over the Amazônia region have been carried out for March and October of 1999 to provide detailed information on surface radiation budget (SRB) and precipitation variability. SRB fluxes and rainfall are the two foremost cloud-modulated control variables that affect land surface processes, and they require specification at space-time resolutions concomitant with the changing cloud field to represent adequately the complex coupling of energy, water, and carbon budgets. These processes ultimately determine the relative variations in carbon sequestration and carbon dioxide release within a forest ecosystem. SRB and precipitation retrieval algorithms using GOES imager measurements are used to retrieve surface downward radiation and surface rain rates at high space-time resolutions for large-scale carbon budget modeling applications in conjunction with the Large-Scale Biosphere-Atmosphere Experiment in Amazônia. To validate the retrieval algorithms, instantaneous estimates of SRB fluxes and rain rates over $8 \mathrm{~km} \times 8 \mathrm{~km}$ areas were compared with 30-min-averaged surface measurements obtained from tower sites located near Ji-Paraná and Manaus in the states of Rondônia and Amazonas, respectively. Because of large aerosol concentrations originating from biomass burning during the dry season (i.e., September and October for purposes of this analysis), an aerosol index from the Total Ozone Mapping Spectrometer is used in the solar radiation retrieval algorithm. The validation comparisons indicate that bias errors for incoming total solar, photosynthetically active radiation (PAR), and infrared flux retrievals are under $4 \%, 6 \%$, and $3 \%$ of the mean values, respectively. Precision errors at the analyzed spacetime scales are on the order of $20 \%, 20 \%$, and $5 \%$. The visible and infrared satellite measurements used for precipitation retrieval do not directly detect rainfall processes, and yet they are responsive to the rapidly changing cloud fields, which are directly associated with precipitation life cycles over the Amazon basin. In conducting the validation analysis at high space-time scales, the comparisons indicate systematic bias uncertainties on the order of $25 \%$. These uncertainties are comparable to published values from an independent assessment of bias uncertainties inherent to the current highest-quality satellite retrievals, that is, from the Tropical Rainfall Measuring Mission. Because precipitation is a weak direct control on photosynthesis for the Amazon ecosystem, that is, photosynthesis is dominated by the strong diurnal controls of incoming PAR and ambient air-canopy temperatures, such uncertainties are tolerable. By the same token, precipitation is a strong control on soil thermal properties and carbon respiration through soil moisture, but the latter is a time-integrating variable and thus inhibits introduction of modeling errors caused by random errors in the precipitation forcing. The investigation concludes with analysis of the monthly, daily, and diurnal variations intrinsic to SRB and rainfall processes over the Amazon basin, including explanations of how these variations arise during wet- and dry-season periods.
\end{abstract}

\section{Introduction}

A major scientific objective of the Large-Scale Biosphere-Atmosphere Experiment (LBA) in Amazônia is

Corresponding author address: Eric A. Smith, NASA Goddard Space Flight Center, Code 912.1, Greenbelt, MD 20771-0001.

E-mail: eric.a.smith@nasa.gov to understand the carbon budget and carbon sequestering capacity of the forest-pasture system that dominates the landscape and the space-time heterogeneity manifest in carbon fluxes across the whole region. This process is arduous to quantify, requiring an admixture of observations and modeling to decipher the complexity of the variability and the predominant controls on the vari- 
ability. In this multiple-part investigation, a combination of in situ measurements, remotely sensed measurements from space, and a coupled and observationally forced hydrometeorological-carbon assimilation (hydrometcarbon) model, capable of simulating the details of the surface energy and water budgets as well as the principal modes of photosynthesis and respiration, is developed to study variations in the Amazonian carbon budget.

In Part 1 of this investigation, the method and validation of the principal remote sensing forcing variables are developed, that is, incoming radiation fluxes and precipitation, followed by a space-time analysis of their variational properties over the Amazon basin. The individual retrieval parameters are the surface incoming solar $(K \downarrow)$, infrared $(L \downarrow)$, and photosynthetically active (PAR $\downarrow$ ) radiation fluxes, plus surface rain rates (RR) on 8-km/30-min space-time spacings over the large-scale Amazon basin. [Note that the PAR spectrum extends from 0.4 to $0.7 \mu \mathrm{m}$.] Retrievals from wet- and dryseason periods are then analyzed for their inherent space-time variations to understand carbon budget variability as will be described in Part 2. In Part 2, development and validation of the coupled hydromet-carbon model will be investigated, along with a preliminary analysis of carbon budget processes and variability.

Incoming surface radiation budget (SRB) fluxes and rainfall are key forcing variables in biosphere-atmosphere carbon exchange processes (Norman et al. 1992; Haxeltine and Prentice 1996). Recent studies based on surface measurements of net ecosystem exchange (NEE) using eddy-correlation techniques have indicated that the undisturbed rain forest may be a net carbon sink (Fan et al. 1990; Grace et al. 1995). However, these investigations have shown that carbon dioxide uptake rate over the Amazônia forest is highly sensitive to radiation and temperature and that the system may change from a sink to a source in response to reduced radiation levels or temperature rises of $1 \mathrm{~K}$ or less. The sensitivity of NEE to environmental variables producing nonlinearities in photosynthesis and respiration processes, the discontinuous nature in space and time of the radiation and rainfall fields induced by clouds controlling the thermal properties of the surface, and the dearth of in situ measurements of carbon fluxes over the extended basin make large-scale and long-term estimates of NEE by means of extrapolation from point measurements prone to large uncertainties. Moreover, it is beyond the capability of current global or limited-area prognostic models to simulate realistically the space-time properties of clouds and, thus, their underlying surface radiation and precipitation effects; for example, see the regional modeling intercomparison study of Takle et al. (1999).

Various datasets of surface radiation and rainfall over the large-scale region of Amazônia are available from experiments such as the Global Energy and Water Cycle Experiment (GEWEX) and the International Satellite Cloud Climatology Project (ISCCP)—see Chahine
(1992), Lawford (1999), and Rossow and Schiffer (1999). These products, though they provide valuable information over the entire globe, typically have a spatial resolution on the order of $1^{\circ}$ or greater and a temporal resolution on the order of 1 month, resolutions that are inadequate for use in modeling systems designed to simulate biomass production, heat and moisture fluxes, and trace gas exchange at the surface (Smith et al. 1992; Cooper et al. 1998; Rahman et al. 2001).

The SRB and precipitation retrievals are obtained from full-resolution Geostationary Operational Environmental Satellite (GOES) imager data collected during March-April (wet season) and September-October (dry season) of 1999 (see Fig. 1 for a schematic of the satellite study area). The radiation retrievals are based on previously developed algorithms designed for forest settings and were first applied to a boreal forest ecosystem (Gu and Smith 1997; Gu et al. 1997). The rainrate retrievals are based on a GOES visible and infrared algorithm (King et al. 1995) calibrated to Global Precipitation Climatology Project (GPCP) monthly analyzed rainfall (Huffman et al. 1997, 2001). The motivation for this approach is to maximize the use of the high-resolution information inherent to GOES measurements while at the same time calibrating to an accepted merged global precipitation data product to mitigate against systematic error effects unavoidable when directly retrieving precipitation from optical and infrared measurements. High-resolution precipitation information is valuable for studies of the Amazon basin. For example, the study of Greco et al. (1990) for the Amazon Boundary Layer Experiment (ABLE-2B) indicated that the rainfall varied considerably with respect to the underlying rain-producing regime, with the dominant regimes changing from season to season and even within seasons.

Section 2 describes the study domain and the various datasets involved in this investigation; section 3 describes the satellite algorithms used to retrieve the $K \downarrow$, $L \downarrow$, PAR $\downarrow$, and RR quantities. Section 4 goes on to validate the retrievals with in situ observations at the European Studies on Trace Gases and Atmospheric Chemistry (EUSTACH) and Tropical Rainfall Measuring Mission (TRMM) ground validation sites. Section 5 then presents the analysis of the spatial and temporal variations of SRB fluxes and rainfall over large-scale Amazônia. Section 6 provides a summary discussion and presentation of final conclusions. Note that the datasets produced for this investigation were available online at http://beija-flor.ornl.gov/lba/ at the time of writing.

\section{Study domain and datasets}

The study domain covers most of the Amazon basin $\left(5^{\circ} \mathrm{N}-16^{\circ} \mathrm{S}, 40^{\circ}-75^{\circ} \mathrm{W}\right)$ as shown with the large, thick rectangle in Fig. 1. Within this domain, an $8 \mathrm{~km} \times 8$ $\mathrm{km}$ equal-area grid is defined for purpose of analyzing 


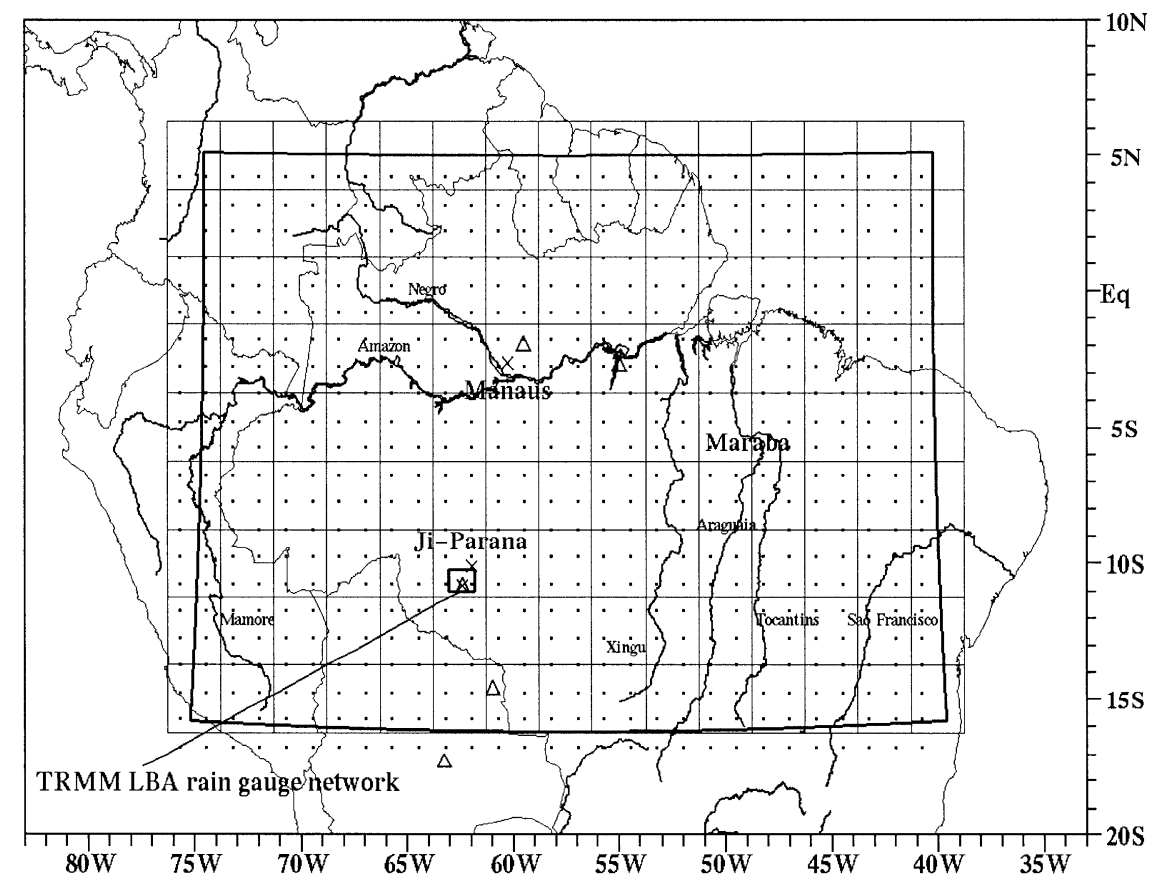

FIG. 1. Boundaries of study area (large thick rectangle), along with TOMS aerosol index grid (dots), NCEP-NCAR reanalysis grid (using thin lines to denote gridcell boundaries), locations of EUSTACH-LBA flux tower sites at Ji-Paraná and Manaus (crosses), AERONET sites (open triangles), and TRMM ground validation site (small thick rectangle at Ji-Paraná).

the GOES measurements. The dominant land cover in the western part of the domain is rain forest, with pasture in Bolivia and Peru and interrupted forest in the central and southeastern regions. The southeastern part of the domain is mostly cleared forest. Most of the domain is relatively flat, with highest elevations in the Andes piedmont to the southwest.

The periods of focus for this investigation are MarchApril of 1999 for the wet season and September-October of the same year for the dry season. It is known that March is one of the wettest months $(\sim 250-350 \mathrm{~mm}$ of rainfall) and September is one of the driest months ( 15-90 mm of rainfall) at Manaus, Ji-Paraná, and Marabá (Gash et al. 1996). The amount of precipitation decreases in April toward the end of the rainy season, with the dry season starting to terminate over most of South America during October.

Measurements from all five GOES imager channels $(0.65,3.9,6.7,11.0$, and $12.0 \mu \mathrm{m})$ were acquired and archived at full space-time resolution $(1,4,8,4$, and 4 $\mathrm{km}$ and half hourly) at The Florida State University during the above-mentioned 4 months. For purpose of the SRB and rainfall retrievals, the visible channel $(0.65$ $\mu \mathrm{m})$ and two split-window thermal infrared channels (11 and $12 \mu \mathrm{m}$ ) were used, as described in section 3 .

Retrieved SRB and RR retrievals are validated against surface observations from three EUSTACH-LBA sites and from a rain gauge network deployed by the National Aeronautics and Space Administration (NASA) TRMM. Surface measurements of half-hourly radiation and as- sociated meteorological variables from two sites at JiParaná and one site at Manaus were used to validate the SRB retrievals. The two sites in Ji-Paraná are in the southwest, consisting of a forest site at the Reserva Biologica do Jaru located at $10^{\circ} 04^{\prime} 41^{\prime \prime} \mathrm{S}, 61^{\circ} 56^{\prime} \mathrm{W}$ and a pasture site at Fazenda Nossa Senhora (FNS) located at $10^{\circ} 45^{\prime} 42^{\prime \prime} \mathrm{S}, 62^{\circ} 21^{\prime} 26^{\prime \prime} \mathrm{W}$. The Manaus site is in undisturbed rain forest in central Amazônia located at $2^{\circ} 36^{\prime} 33^{\prime \prime} \mathrm{S}, 60^{\circ} 12^{\prime} 33^{\prime \prime} \mathrm{W}$. The locations of these three sites are indicated in Fig. 1 as crosses; detailed site descriptions are found in Andreae et al. (2002) and Araújo et al. (2002).

The calibration data used for the rain-rate retrieval algorithm were produced by the GPCP as described by Huffman et al. (2001). The validation data for retrieved rainfall were obtained from 41 rain gauges at Ji-Paraná in Rondônia, with 40 of them from the NASA TRMM ground validation site (Kummerow et al. 2000) and 1 from the EUSTACH-LBA pasture site at FNS. The locations of these rain gauges are within the thick rectangle at Ji-Paraná shown in Fig. 1. The arrangement of the rain gauges in various networks is shown in Fig. 2. The original 1-min data from individual gauges were averaged into a half-hourly time series prior to analysis.

Because of the significant effects of aerosol smoke from biomass burning during the dry season on the surface incoming total solar radiation and PAR fluxes, an aerosol index (AI) from the Total Ozone Mapping Spectrometer (TOMS) was incorporated into the SeptemberOctober SRB retrievals (Herman et al. 1997; Torres et 


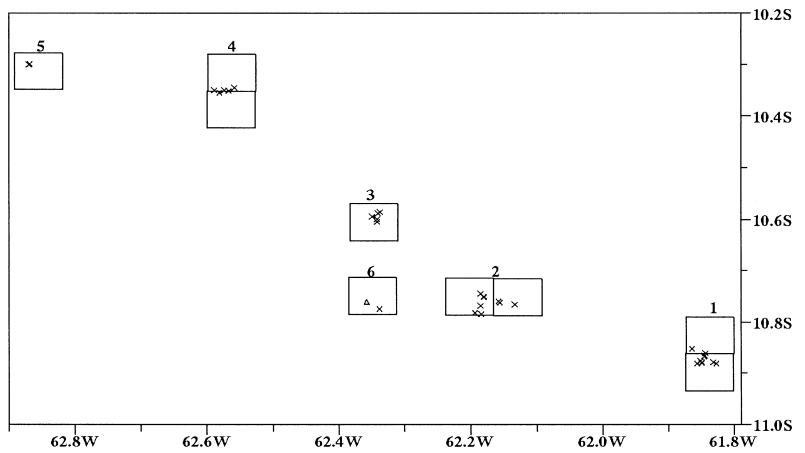

FIG. 2. Locations of 40 TRMM-LBA rain gauges (crosses) and one EUSTACH-LBA rain gauge (triangle) relative to pixels of GOES retrievals (rectangles). Rain gauges are grouped into six networks, as indicated, before comparison with satellite rain-rate retrievals.

al. 1998). TOMS data are available daily at $1.25^{\circ} \times$ $1.0^{\circ}$ spatial resolution (the TOMS grid is illustrated as dots in Fig. 1).

Columnar precipitable water, relative humidity, and air temperature for the SRB retrievals were obtained from National Centers for Environmental PredictionNational Center for Atmospheric Research (NCEPNCAR) reanalysis products (Kalnay et al. 1996). The NCEP-NCAR gridbox boundaries grid, which uses 2.5 -6 -h space-time resolutions, is indicated in Fig. 1 with thin lines.

The vegetation map used to assign surface bidirectional reflectance properties and needed in the calculation of $L \downarrow$ is based on the global land cover characteristics maps of the U.S. Geological Survey (Loveland et al. 2000). The vegetation map was derived from Advanced Very High Resolution Radiometer (AVHRR) data and was produced at a spacing of $1 \mathrm{~km}$. For this investigation, the spacing is reduced to $8 \mathrm{~km}$ by assigning the most dominant land cover type within each $8 \mathrm{~km} \times 8 \mathrm{~km}$ grid square as an explicit vegetation type.

\section{GOES SRB and rain-rate retrieval algorithms}

In this section, the algorithms used to retrieve $K \downarrow$, PAR $\downarrow, L \downarrow$, and RR are described, with focus on modifications made to the original algorithms to ensure consistent validation with the in situ measurements made in Amazônia. Calibrations of the GOES-8 visible and infrared detectors follow the methods described in Weinreb et al. (1997a,b). For the visible channel, the nominal calibration is based on prelaunch laboratory measurements. Previous studies have indicated that the sensitivities of the GOES-8 visible detectors have been deteriorating over a range of $4.6 \%-6.1 \% \mathrm{yr}^{-1}$ (Knapp and Vonder Haar 2000; http://www.oso.noaa.gov/goes/ goes-calibration/vicarious-calibration.html), and, hence, the visible reflectances have been increased $5 \% \mathrm{yr}^{-1}$ (i.e., $0.0137 \%$ day $^{-1}$ ) starting on 13 April 1994, the day of the GOES-8 launch (M. Weinreb 2002, personal communication). We also note the Web site, http://www. cptec.inpe.br/sdatellite/metsat, developed by Centro de Previsão de Tempo e Estudos Climáticos in Brazil, in which various GOES-based solar SRB products are available, products that are generated at longer times scales than we use in this investigation.

\section{a. Incoming total solar radiation/PAR fluxes retrieval}

The surface incoming solar radiation/PAR retrieval algorithm is based on a physical algorithm designed for a forest setting and first applied for a boreal forest ecosystem (Gu and Smith 1997). The design of the algorithm follows a method originally developed by Gautier et al. (1980) and improved upon by Diak and Gautier (1983), Frouin et al. (1989), and Gautier and Landsfeld (1997). The algorithm uses GOES visible radiances to determine the visible reflectance of land surfaces and clouds. The effects of other physical processes, including Rayleigh scattering, water vapor and ozone absorption, aerosol attenuation, and cloud absorption of incoming solar radiation, are all parameterized.

Modifications to the original algorithm developed by Gautier and her colleagues for calculations of surface albedo, aerosol attenuation, and cloud absorption had been made prior to LBA applications as discussed in $\mathrm{Gu}$ and Smith (1997). In moving to a tropical rain forest regime, further modifications were required for calculation of cloud absorption, modifications essential to reduce a positive bias error found in the $K \downarrow$ and PAR $\downarrow$ retrievals when using the initially modified parameterization. In Gu and Smith (1997), cloud absorption for the total solar radiation and PAR bands had been calculated as $20 \%$ and $3 \%$ of cloud visible reflectance, respectively. We found that whereas such a parameterization is satisfactory for a high-latitude forest, it is too much of an oversimplification of the microphysics involved in the interaction between clouds and the radiation field for the more complex convective cloud structures found in the Tropics, leading to overestimations of both $K \downarrow$ and PAR $\downarrow$ at the surface.

There are several reasons for these results in the Tropics. First, unlike higher latitudes, Amazônia frequently produces deep convective clouds within a moist trade wind environment. Because of the larger cloud droplets in such clouds, they are generally less reflective and more absorptive than clouds at high latitudes. This result has also been found in the studies of Menzel et al. (1990), Li et al. (1995), and Lubin et al. (1996). Second, the mean solar zenith angle in the Tropics is considerably smaller than at high latitudes, and therefore cloud albedo is lower because of the nonlinear behavior of directional reflectance from a cloud surface, which increases with increasing zenith angle ( $\mathrm{Gu}$ et al. 1997). Third, during the dry season, the presence of graphitic carbon from biomass burning tends to reduce cloud reflectance in the visible channel (Kaufman and Nakajima 1993). Therefore, the initial cloud absorption parame- 
TABLE 1. Coefficients for Eq. (2) derived from in situ measured radiation and relative humidity from Jaru forest and Fazenda Nossa Senhora pasture sites at Ji-Paraná. Regressions use data collected in Apr and Sep 1999. Correlation coefficient and root-mean-square error between retrieved and observed $L^{*}$ are indicated as $r$ and rms; $N$ is number of samples used in regression. Relative humidity sensor at Fazenda Nossa Senhora was out of order in Sep and therefore relative humidity measurements used for regression are from Jaru forest site.

\begin{tabular}{|c|c|c|c|c|c|c|c|}
\hline & $a_{0}$ & $a_{1}$ & $a_{2}$ & $a_{3}$ & $r$ & $\mathrm{rms}\left(\mathrm{W} \mathrm{m}^{-2}\right)$ & $N$ \\
\hline Wet-season forest & -105.61 & -43.91 & 1.09 & 0.71 & 0.76 & 12.0 & 1322 \\
\hline Wet-season pasture & -102.14 & -74.26 & 0.79 & 0.81 & 0.86 & 11.7 & 1338 \\
\hline Dry-season forest & -114.56 & -38.86 & 0.92 & 0.80 & 0.80 & 11.9 & 1318 \\
\hline Dry-season pasture & 13.90 & -62.73 & -2.12 & 0.30 & 0.89 & 12.1 & 1273 \\
\hline
\end{tabular}

terization underestimates cloud attenuation and thus overestimates fluxes of $K \downarrow$ and PAR $\downarrow$ at the surface.

To account for reduction of radiation at the surface by less reflective clouds without seeking to account for unmanageable details in defining cloud microphysical properties, cloud absorptances for PAR and total solar radiation wavelengths are increased. For clouds with reflectances less than 0.35 , the total solar radiation and PAR absorptance factors are set to $45 \%$ and $32 \%$ of cloud reflectance; for clouds with reflectances greater than 0.35 but less than 0.5 , the absorptance factors are set to $30 \%$ and $22 \%$; and for clouds with reflectances greater than 0.5 , the absorptance factors are set to $20 \%$ and $15 \%$. This parameterization is consistent with, but not equivalent to, the cloud absorptance parameterization in the 2001 version of Gautier's algorithm based on a study using a detailed radiative transfer model (Gautier and Landsfeld 1997), the difference being our calculations use modified absorptance factors. The same parameterization is used in the dry season to account for the less reflective cloud effect. However, because of enhanced aerosol reflectance by smoke from biomass burning (which further reduces cloud reflectance), the cloud absorptance factors require small additional adjustments.

For the dry-season aerosol correction, the TOMS-AI was converted into aerosol optical depth $(\tau)$ according to the procedure of Hsu et al. (1999), given by the following relationship:

$$
\tau=0.6338+0.903 \mathrm{AI} .
$$

This relationship was obtained from the 1999 TOMS aerosol index and in situ aerosol optical depth measurements at five Aerosol Robotic Network (AERONET) sites as indicated by triangles in Fig. 1; see Holben et al. (1998) for a description. The correlation coefficient between $\tau$ and AI during the dry season from this dataset is 0.91. During the wet season, the correlation coefficient decreases to 0.63 . Given the considerably lower concentrations of aerosol present during the wet season, as well as the decreased correlation between $\tau$ and AI, a constant aerosol optical depth of 0.04 has been used for wet-season analysis. Of note, an anonymous reviewer has pointed out to us that there is now research under way to seek a means to adjust the TOMS-AI in conjunction with variations in the vertical distribution of smoke aerosol.

\section{b. Incoming infrared radiation flux retrieval}

The $L \downarrow$ retrieval scheme is statistical in nature and was also developed for forest ecosystems $(\mathrm{Gu}$ et al. 1997, 1999). The scheme used atmospheric transmittance at solar wavelengths $\left(\mathrm{TR}_{a}\right)$ and radiometric surface temperature $\left(T_{s}\right)$, both retrievable from GOES imager data, as the principal independent variables to estimate surface net infrared radiation $\left(L^{*}\right)$. Flux $L \uparrow$ was then obtained as a residual from the infrared balance equation $L^{*}=L \downarrow-L \uparrow$ in which the upwelling flux was calculated as a broadband flux quantity from the associated GOES-retrieved value of $T_{s}$. Considering the larger amount of atmospheric moisture in tropical regions in comparison with high latitudes and the substantial influence of low-level moisture on $L^{*}$ (Liou 1992), we introduce relative humidity (RH) as a third independent variable for the modified $L^{*}$ retrieval. Regression coefficients for the retrieval relationship are derived from in situ measurements of $L^{*}, L \uparrow, K \downarrow$, and $\mathrm{RH}$ obtained at the EUSTACH-LBA sites, in which $L^{*}$ is formulated as follows:

$$
L^{*}=a_{0}+a_{1} \mathrm{TR}_{a}+a_{2}\left(T_{s}-273.15\right)+a_{3} \mathrm{RH},
$$

with the regression coefficients $a_{i}$ given in Table 1 . The regression equation for $T_{s}$ is obtained from the GOES8 split-window channels 4 and 5 according to

$$
T_{s}=T_{4}+b_{1}\left(T_{4}-T_{5}\right)+b_{2}\left(T_{4}-T_{5}\right)^{2}+b_{0},
$$

where $T_{4}$ and $T_{5}$ are equivalent blackbody temperatures (in kelvins) and regression coefficients $b_{i}$ are given in Table 2.

It should be noted that even though Eq. (3) is valid for both clear and cloudy atmospheres, in reality it is only applicable for clear-sky conditions when $T_{s}$ is retrievable from GOES imager measurements. For boreal forest applications, a special interpolation procedure was developed to estimate $T_{s}$ below clouds using $T_{s}$ values from surrounding clear areas. Such a procedure is not appropriate for the Amazon basin because of the extensive cloud cover during the wet season and the presence of mountains in the western and northern part of the domain. Therefore, in cloudy regions, $L \downarrow$ is calculated directly according to a relationship developed by Bastable et al. (1993) for specific applications within the Amazon basin. 
TABle 2. Coefficients for Eq. (3) derived from in situ measured radiation at Jaru forest and Fazenda Nossa Senhora pasture sites at JiParaná and GOES channel-4 and -5 radiance measurements. Regressions use data collected in Apr and Sep 1999. Correlation coefficient and root-mean-square error between retrieved and observed $T_{s}$ are indicated as $r$ and rms; $N$ is number of samples used in regression.

\begin{tabular}{lccrrr}
\hline \hline & $b_{0}$ & $b_{1}$ & $b_{2}$ & $r$ & $N$ \\
\hline Wet-season forest & 2.555 & 2.689 & -0.379 & 0.966 & 1.06 \\
Wet-season pasture & 1.296 & 3.338 & -0.397 & 0.981 & 0.79 \\
Dry-season forest & 1.800 & 2.358 & -0.239 & 0.960 & 1.08 \\
Dry-season pasture & 1.837 & 1.936 & 0.005 & 0.966 & 58 \\
\hline
\end{tabular}

$$
L \downarrow=\varepsilon_{a}\left(1+0.2 f_{c}^{2}\right) \sigma T_{a}^{4},
$$

where

$$
\varepsilon_{a}=0.65+0.007\left(T_{a}-273.16\right)
$$

Here, $f_{c}$ is the cloud fraction determined from GOES measurements, $\varepsilon_{a}$ is the emissivity of clear sky, $T_{a}$ is the near-surface air temperature, and $\sigma$ is the StefanBoltzmann constant. It is important to recognize that whereas the approach we have taken to retrieve incoming infrared radiation flux is adequate for the moist boundary layer conditions characteristic of rain-forest regions, retrieval of this surface radiation budget parameter remains an active topic of research that will likely only significantly improve in correspondence with improvements made in the retrieval of the vertical microphysical structure of clouds.

\section{c. Rain-rate retrieval}

As discussed earlier, the design of the rain-rate retrieval algorithm used in this investigation is tailored for our particular modeling problem, that is, forcing a coupled hydromet-carbon model at high temporal and spatial resolutions with tolerable systematic error uncertainty. An effective data source for meeting the scale requirements is the imager instrument on the GOES. In truth, visible (VIS) and infrared (IR) measurements are not ideal for rainfall retrieval because they can only be statistically related to precipitation through macrophysical cloud properties and thus necessarily give rise to both systematic and random rainfall uncertainties to degrees dependent upon the inherent space-time scales.

The most important consideration with the rainfall forcing data in the context of the physical system being modeled is to remove the systematic errors to the degree possible. At the 8-km-30-min scales of interest here, our greatest concern is with these types of error, because they produce concomitant systematic errors in soil moisture, surface moisture fluxes, and surface thermal properties. In turn, systematic errors in soil respiration of carbon will arise, because respiration is related in a nonlinear fashion to both the thermal conditions and the water content of the soil-see Bonan (1996) and Meir et al. (1996) for background on this topic. In this context, there are realistic limits to which rainfall bias uncertainties can be reduced. Whereas there is a long-lived and vast literature on this topic, a recent investigation by Kummerow et al. (2000) has evaluated this issue from a satellite perspective enabled by data available from TRMM. This investigation conservatively places the systematic uncertainty threshold that can be achieved in estimating satellite-based monthly averaged rain rates at a $500-\mathrm{km}$ spatial scale at approximately $25 \%$ (the published value is $24 \%$ ). We take this as a credible and realistic goal for systematic error uncertainty in the estimation of rainfall from GOES measurements.

In considering the influence of the random error component of rainfall estimates on carbon budget modeling, it is important to recognize that precision errors are largely mitigated by the time-integrating process of soil moisture. Therefore, the modeling system used to calculate variations in the carbon budget tolerates a good degree of random noise in the rainfall forcing. Because the thermal response of soil and the decay rate of biomass can only respond slowly to changes in soil moisture, which itself is a damped variable vis à vis rainfall fluctuations, rapid noise fluctuations in the precipitation forcing of a coupled hydromet-carbon model tend to produce only small errors relative to the overall errors produced by systematic offsets in the precipitation forcing. Moreover, as will be stressed in the Part- 2 investigation, precision errors in precipitation forcing have negligible direct effects on coupled transpiration-photosynthesis processes in rain forests. Because this mechanism is the only one by which instantaneous rain-rate precision error can directly influence the modeling calculations, they are of minor concern in evaluating the space-time variations of the carbon budget. These are the main considerations in our choice of precipitation retrieval method.

The precipitation retrieval algorithm is based on a supervised classification procedure developed by King et al. (1995) for applications with both VIS and thermal IR measurements (GOES imager channels 1 and 4) to obtain the high-resolution, rapidly evolving relativechange characteristics of the precipitation field. These results are then calibrated to a monthly analyzed, $1^{\circ}$ resolution, merged data product developed by the GPCP (Huffman et al. 1997, 2001). During the daytime period, both VIS and IR measurements are used for the initial retrievals; at night only IR measurements are used.

The supervised classification algorithm was originally calibrated over southern Ontario, Canada, by using coincident GOES-7 and weather radar data collected during two summers (June, July, and August of 1987 and 
1988). It was found during its application within the first Algorithm Intercomparison Project (AIP-1) of the GPCP that its correlation and bias statistics were superior to any other VIS-IR or IR-only algorithm when compared with validation data collected from Japan (Arkin and Xie 1994). However, based on the validation procedure for AIP-1, the mean magnitudes of the rain rates were underestimated by a factor ranging from 1.3 to 2.6. In comparing the classification algorithm's results from the Amazon with those from in situ measurements collected at the TRMM ground validation site and the EUSTACH-LBA FNS site, the same low bias noted in the AIP-1 study was found.

To eliminate the possibility of a low bias caused by environmental differences between Ontario and Brazil, the classification algorithm is calibrated to the GPCP merged monthly estimates from the Amazon basin. This dataset represents the merger of quality-controlled climatic rain gauge station data time series within the Amazon to microwave radiometer-radar estimates from the TRMM observatory, microwave radiometer estimates from Special Sensor Microwave Imager (SSM/I) instruments, and infrared imager estimates from GOES. The satellite products are all bias-adjusted to the blended rain gauge estimates - that is, the rain gauge measurements represent the calibration reference for all the blended satellite products, including the GOES estimates (Huffman 1997). That is why we chose the GPCP product as a calibration source for our GOES precipitation estimates from the classification algorithm. An independent study by Negri et al. (2000), which used GOES data to generate monthly rainfall estimates over the Amazon for a 10-yr period, produced results in qualitative agreement with the GPCP monthly estimates, particularly in terms of spatial distribution. This result provides additional evidence that a GOES-based precipitation dataset can be effectively calibrated with GPCP estimates over the Amazon.

Besides the calibration process, one additional modification to the initial classification algorithm has to be included that involves the input variables of VIS reflectance and channel-4 equivalent blackbody temperature (EBBT). This stems from its application over the mountainous regions near the southwest corner of the study area, where rain rates, left unchecked, would be overestimated to a greater degree than over the lowlying regions of the basin. This is a direct result of the higher surface albedos and lower surface temperatures associated with high elevations influencing the classification process for any given satellite measurement. To correct for the elevation effects on the outgoing satellite radiances, which themselves change from wet season to dry season, requires an adjustment of the VIS reflectance $\left(R_{\text {vis }}\right)$ and the channel-4 EBBT $\left(T_{4}\right)$ used in classifying rain rates. The adjustments are applied as follows:

$$
\begin{aligned}
& R_{\mathrm{vis}}^{\mathrm{adj}}=R_{\mathrm{vis}}-R_{\mathrm{vis}}^{\min }+R_{0} \text { and } \\
& T_{4}^{\mathrm{adj}}=T_{4}-T_{4}^{\max }+T_{0},
\end{aligned}
$$

where $R_{\mathrm{vis}}^{\min }$ and $T_{4}^{\max }$ are obtained from monthly halfhourly extreme value composites of minimum visible reflectance and maximum channel-4 EBBT maps and $R_{0}$ and $T_{0}$ are compensation constants determined by statistical regression. The values derived for $R_{0}$ and $T_{0}$ are 0.07 and $305 \mathrm{~K}$ for the wet season and 0.18 and $298 \mathrm{~K}$ for the dry season, respectively.

\section{Validation of retrievals with in situ observations}

In this section, satellite-retrieved surface radiation and rain-rate quantities from the algorithms described in section 3 are validated with respect to in situ observations. It is important to note that the satellite retrievals are instantaneous values that cover $8 \mathrm{~km} \times 8 \mathrm{~km}$ areas, whereas the in situ radiation measurements are halfhourly averaged point measurements and the in situ rain measurements are daily averaged gauge observations from the 41 individual rain gauges distributed over the TRMM validation site. Therefore, the retrievals are not of identical scale and thus are not identical variableseven if both quantities are error free and/or equivalent in value. To carry out the validation for rain rate, the 41 rain gauges are grouped into six networks according to the locations of the individual gauges, as shown in Fig. 2. Each network consists of between 2 and 14 gauges. To form a daily validation value for testing against the calibrated daily value derived from the GPCP estimates located within the GPCP grid box situated over the TRMM site, lumped gauge daily means from the six individual networks are used to form the daily averages.

Validation results for the incoming radiation fluxes during the SRB validation months (April and September) are shown in Table 3 in terms of correlation $(r)$, mean difference (MD), and relative root-mean-square (rms) error. For both months, the correlation coefficients of satellite-retrieved and measured $K \downarrow$ and PAR $\downarrow$ are high (0.94-0.96). The bias errors are only a few watts per square meter, except for $K \downarrow$ at the pasture site. The precision errors are $16 \%-25 \%$ of the mean observed values. For $L \downarrow$, the correlation drops to under 0.70 , and the relative precision errors are less than $7 \%$ of the mean values. The lower correlations for $L \downarrow$ are more associated with the small natural variations of downwelling infrared fluxes in a moist environment than they are with the retrieval scheme-a property of the fluxes that also leads to the relatively small rms errors. For a drier atmosphere, the simplicity of an empirical $L \downarrow$ retrieval scheme can be more problematic (e.g., Gu et al. 1997). However, for the Tropics, the overall magnitude of $L \downarrow$ uncertainty is so small as not to be of concern for carbon budget modeling.

Table 4 gives the validation results when the SRB algorithms are applied to the validation months of 
TABLE 3. Statistical comparison between retrieved and observed incoming total solar radiation ( $K \downarrow)$, PAR (PAR $\downarrow)$, and infrared radiation $(L \downarrow)$ fluxes for calibration months (Apr and Sep 1999), where $N$ is number of comparison samples, $r$ is correlation coefficient, ave is mean value of in situ observations, MD is mean difference between retrieved and observed (i.e., ave-ret minus ave-obs), and rms is relative rms error. Observations are from three EUSTACH-LBA sites shown in Fig. 1.

\begin{tabular}{|c|c|c|c|c|c|c|}
\hline & $\begin{array}{c}\text { Flux } \\
\text { quantity }\end{array}$ & $N$ & $r$ & Ave $\left(\mathrm{W} \mathrm{m}^{-2}\right)$ & $\mathrm{MD}\left(\mathrm{W} \mathrm{m}^{-2}\right)$ & Rms (\%) \\
\hline \multicolumn{7}{|c|}{ Wet season (Apr) } \\
\hline \multirow[t]{3}{*}{ FNS pasture } & $K \downarrow$ & 599 & 0.948 & 481.10 & -2.58 & 19.0 \\
\hline & PAR $\downarrow$ & 599 & 0.949 & 213.87 & 3.33 & 19.0 \\
\hline & $L \downarrow$ & 1194 & 0.686 & 408.39 & 0.47 & 5.7 \\
\hline \multirow{3}{*}{ Jaru forest } & $K \downarrow$ & 598 & 0.938 & 460.11 & 0.33 & 22.0 \\
\hline & PAR $\downarrow$ & 598 & 0.939 & 210.26 & 0.80 & 21.5 \\
\hline & $L \downarrow$ & 1195 & 0.595 & 417.58 & -3.62 & 5.6 \\
\hline \multicolumn{7}{|c|}{ Dry season (Sep) } \\
\hline \multirow[t]{3}{*}{ Manaus forest } & $K \downarrow$ & 486 & 0.949 & 422.75 & 3.30 & 22.7 \\
\hline & PAR $\downarrow$ & 486 & 0.951 & 181.82 & 1.46 & 22.0 \\
\hline & $L \downarrow$ & 894 & 0.399 & 422.86 & -10.05 & 5.9 \\
\hline \multirow[t]{3}{*}{ FNS pasture } & $K \downarrow$ & 464 & 0.947 & 464.00 & -13.38 & 18.7 \\
\hline & PAR $\downarrow$ & 141 & 0.937 & 169.01 & 3.38 & 25.0 \\
\hline & $L \downarrow$ & 895 & 0.676 & 414.70 & 3.88 & 6.9 \\
\hline \multirow[t]{3}{*}{ Jaru forest } & $K \downarrow$ & 466 & 0.962 & 474.77 & -3.10 & 16.2 \\
\hline & PAR $\downarrow$ & 466 & 0.962 & 195.30 & 2.81 & 17.0 \\
\hline & $L \downarrow$ & 894 & 0.600 & 418.32 & -1.25 & 6.2 \\
\hline
\end{tabular}

March (wet season) and October (dry season). For the wet season, the correlation coefficients between retrieved and observed SRB fluxes only decrease slightly and the relative rms errors only increase slightly. With one exception, the retrieved $K \downarrow$ and PAR $\downarrow$ fluxes exhibit small positive bias errors while the retrieved $L \downarrow$ fluxes exhibit small negative bias errors. The biases suggest that clouds in March are generally geometrically thicker than those in April. We suspect that the cause of the one larger positive bias for $K \downarrow$ and PAR $\downarrow$ at the Jaru forest site (51 and $22 \mathrm{~W} \mathrm{~m}^{-2}$, respectively) may be due to instrumentation malfunctions that took place at the beginning of site operations near the end of March of 1999 , considering that biases at the nearby pasture site are much smaller, that is, 14 and $9 \mathrm{~W} \mathrm{~m}^{-2}$, respectively.
For the dry season, the validation correlation coefficients and rms errors do not deteriorate. As with the wet season, from site to site, small bias errors appear, with both positive and negative sign differences occurring for $K \downarrow$ and PAR $\downarrow$ and consistently small bias errors with only negative sign differences occurring for $L \downarrow$. This tendency for small but consistent $L \downarrow$ underestimates suggests that clouds in October may have higher cloud bases than in September at the onset of the dry season (thus reduced downwelling infrared radiation fluxes), noting the $L \downarrow$ retrieval algorithm does not respond to small cloud-base variations. We presume that the sign changes in the site-to-site biases for $K \downarrow$ and PAR $\downarrow$, even at the FNS pasture and Jaru forest sites, which are close to one another, are indicative of the underlying bias uncertainty

TABLE 4. Same as in Table 3 but for validation months (Mar and Oct 1999).

\begin{tabular}{|c|c|c|c|c|c|c|}
\hline & $\begin{array}{c}\text { Flux } \\
\text { quantity }\end{array}$ & $N$ & $r$ & $\begin{array}{c}\text { Ave } \\
\left(\mathrm{W} \mathrm{m}^{-2}\right)\end{array}$ & $\begin{array}{c}\mathrm{MD} \\
\left(\mathrm{W} \mathrm{m^{-2 }}\right)\end{array}$ & $\operatorname{Rms}(\%)$ \\
\hline \multicolumn{7}{|c|}{ Wet season (May) } \\
\hline \multirow[t]{3}{*}{ FNS pasture } & $K \downarrow$ & 641 & 0.934 & 413.57 & 13.93 & 23.5 \\
\hline & PAR $\downarrow$ & 612 & 0.935 & 179.86 & 9.00 & 23.9 \\
\hline & $L \downarrow$ & 1213 & 0.535 & 419.06 & -5.36 & 4.4 \\
\hline \multirow[t]{3}{*}{ Jaru forest } & $K \downarrow$ & 111 & 0.915 & 370.90 & 50.86 & 28.8 \\
\hline & PAR $\downarrow$ & 111 & 0.917 & 172.92 & 21.81 & 27.6 \\
\hline & $L \downarrow$ & 213 & 0.524 & 427.33 & -7.71 & 3.7 \\
\hline \multicolumn{7}{|c|}{ Dry season (Oct) } \\
\hline \multirow[t]{3}{*}{ Manaus forest } & $K \downarrow$ & 608 & 0.966 & 468.89 & -6.05 & 16.7 \\
\hline & PAR $\downarrow$ & 608 & 0.967 & 197.37 & 0.24 & 17.2 \\
\hline & $L \downarrow$ & 1215 & 0.414 & 421.63 & -12.16 & 6.0 \\
\hline \multirow[t]{3}{*}{ FNS pasture } & $K \downarrow$ & 516 & 0.963 & 434.01 & 12.95 & 17.8 \\
\hline & PAR $\downarrow$ & 522 & 0.958 & 179.57 & 10.94 & 20.3 \\
\hline & $L \downarrow$ & 1063 & 0.611 & 413.49 & -7.72 & 5.8 \\
\hline \multirow[t]{3}{*}{ Jaru forest } & $K \downarrow$ & 590 & 0.964 & 471.84 & -19.99 & 17.1 \\
\hline & PAR $\downarrow$ & 592 & 0.964 & 192.87 & -1.40 & 17.6 \\
\hline & $L \downarrow$ & 1218 & 0.537 & 414.41 & -9.38 & 6.1 \\
\hline
\end{tabular}


TABLE 5. Monthly statistical comparisons between daily GOES-retrieved rain rates and both daily TRMM and daily "single gridbox" GPCP rain rates over TRMM gauge network domain, that is, equivalent to one GPCP grid box. Wet- and dry-season GOES rain-rate scale factor are 3.95 and 1.75 , respectively.

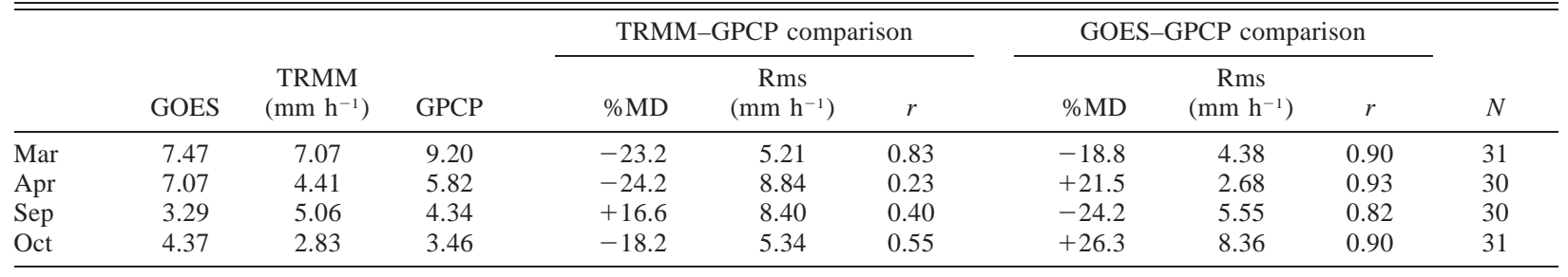

as determined from point-scale observations for the retrieved incoming solar radiation fluxes.

Monthly intercomparison statistics for the GOES-retrieved rain rates relative to the GPCP estimates over the TRMM network domain are given in Table 5 along with similar statistics that intercompare the TRMM rain gauge observations with the GPCP estimates. The correlation coefficients between the daily averaged GOES retrievals and the GPCP estimates are relatively large $(0.82-0.93)$ whereas the correlations between the TRMM observations and the GPCP estimates are considerably smaller $(0.23-0.83)$. This difference in intercomparison statistics is ultimately the result of intercomparing point quantities with volume quantities regardless of the fact that lumped means were calculated within the six gauge networks first. By the same token, the monthly biases between either the GOES-retrieved and GPCP data or the TRMM-observed and GPCP data all fall within 25\%-which is the current expected uncertainty for monthly means at the gridbox scale (Kummerow et al. 2000).

Graphic illustrations of the monthly averaged GOESretrieved fields alongside similar fields for the GPCP estimates are shown in Fig. 3a (April and September) and Fig. 3b (March and October). The salient features in these diagrams are that at the large scale the two precipitation fields are qualitatively similar whereas at the smaller scales the GOES retrievals preserve more subsynoptic details and, in some cases, the remnants of long-lived mesoscale precipitation systems.

In examining the network of rain gauges used by the Global Precipitation Climatology Center (GPCC; Hamburg, Germany) used for calibrating the various satellite retrieval sources that are blended into the GPCP estimates, it is found that some areas of the Amazon-in particular in northern Piauí State, northern Tocantins State, and northern-western Amazonas State of Brazil, parts of the Amazonas and Bolivar States in Venezuela, the Amazonian region of Columbia, and northeastern Peru-there are few or no calibrating gages. In these regions, the calibration factors must be derived from neighboring regions where calibration gauges are located, making it difficult to interpret the detailed differences evident in the figures. Nonetheless, the GOESGPCP correlations, based on using daily values from all grid boxes across the entire domain, are even higher than those found in Table 5 for just the TRMM domain. This result means that the GPCP fields, which are dominated by satellite information, including GOES infrared retrievals, are observing the same spatial-temporal phenomena found in the GOES-only retrievals.

\section{Space-time characteristics of SRB fluxes and rainfall}

In the following sections, salient features of the retrieved areawide monthly surface radiation and precipitation fields over Amazônia are presented, along with discussion of the key space-time variability in these fields. Each of the four data months had a small amount of data missing (less than 3\%,3\%,6\%, and 3\%, respectively). Because the gaps were few and far between, to facilitate time series analysis and in calculating daily and monthly averages, we used linear interpolation of the retrieved radiation and precipitation fields in both space and time to account for missing satellite observations. Note that the months of March and October, which provide the greatest contrast between wet- and dry-season conditions and thus are the months of focus for the analysis, possessed the fewest data gaps in the satellite observations.

\section{a. Monthly wet-dry-season variability}

Figure 4 illustrates the monthly averaged incoming $K \downarrow$, PAR $\downarrow, L \downarrow$, and RR fields for March and October. It is apparent that in March the flux patterns of $K \downarrow$ and PAR $\downarrow$ correlate well (in the inverse) with those of precipitation. The $K \downarrow$ and PAR $\downarrow$ fluxes are generally smaller over the central parts of the rain forest, except for local maxima induced by the effects of local river-breeze circulations. Clouds are suppressed directly over the river and develop a few kilometers inland away from the riverbanks. Larger fluxes are observed in the southeastern part of the domain where much of the forest is interrupted by clearings, crops, and pasturelands. The larger $K \downarrow$ and PAR $\downarrow$ fluxes in the northern and southeastern part of the domain during the wet season correlate well with reduced rainfall, whereas the smaller fluxes in the southwest and along the Amazon River basin correlate well with the enhanced rainfall in these regions. 

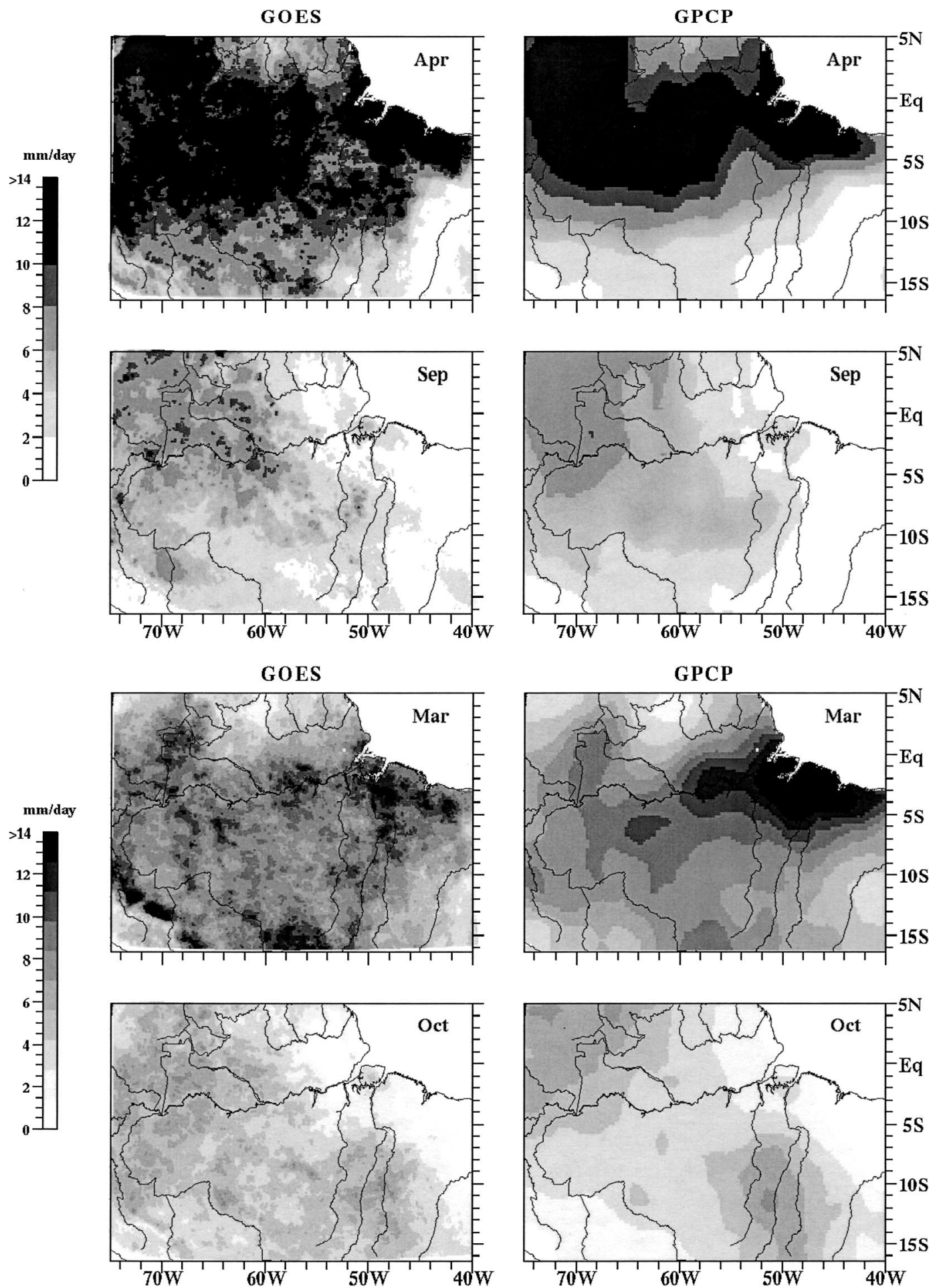

FIG. 3. Comparisons between monthly GPCP rain-rate estimates and GOES-retrieved rain rates over large-scale Amazon study area for (a) Apr and Sep and (b) Mar and Oct 1999. One-degree GPCP estimates are smoothed with two-dimensional, nine-point binomial filter. 
March 1999
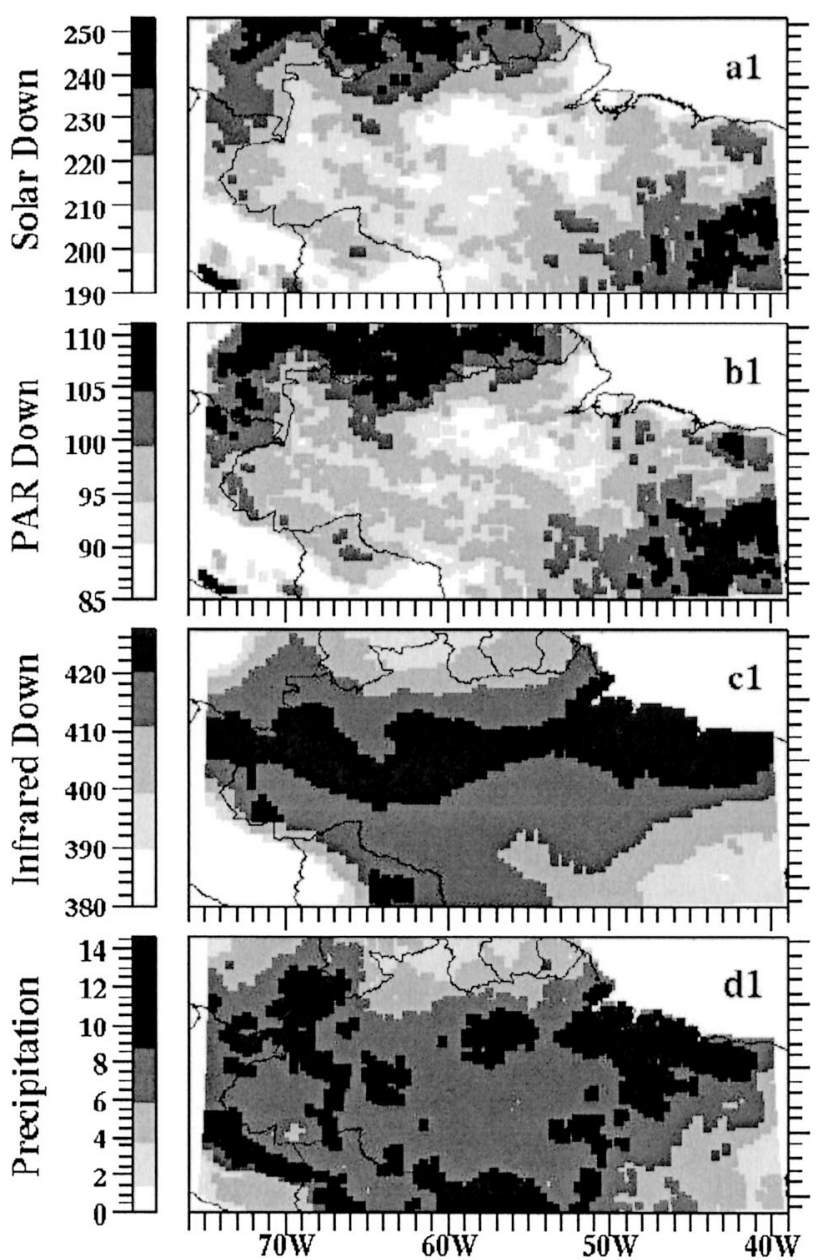

\section{October 1999}
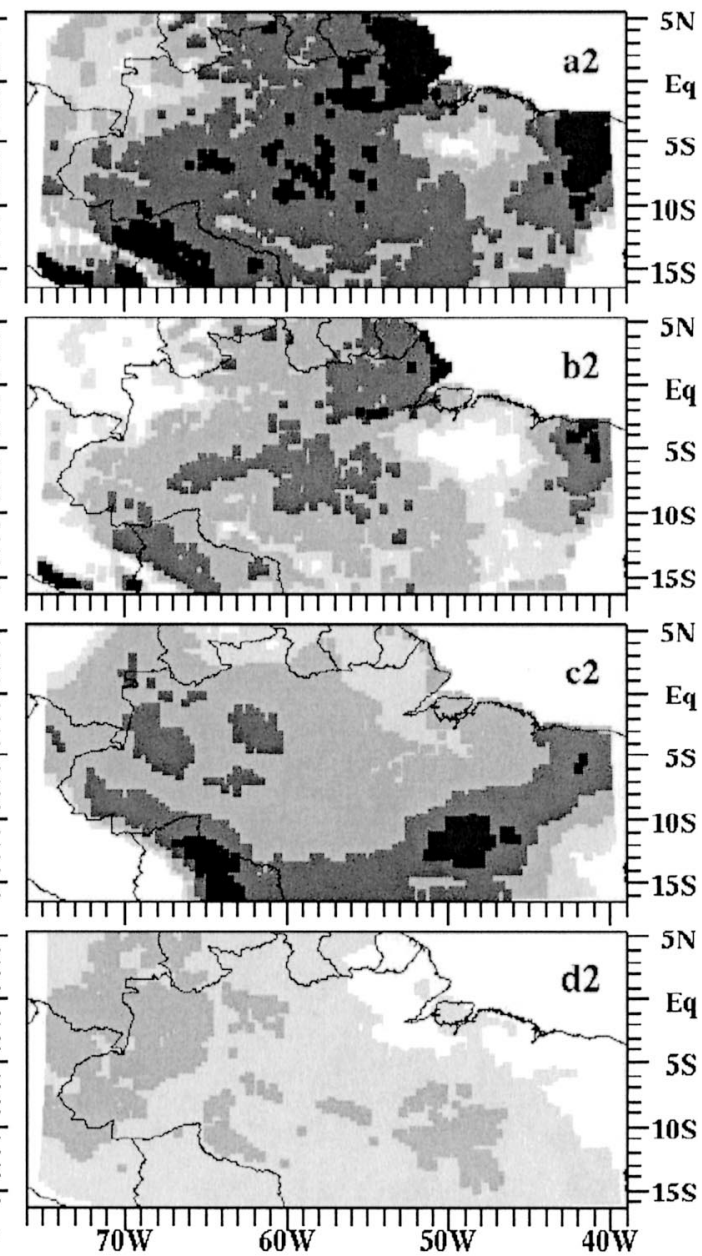

FIG. 4. Monthly averaged incoming total solar radiation, PAR, and infrared radiation fluxes (W $\mathrm{m}^{-2}$ ) along with monthly cumulative rainfall $\left(\mathrm{mm} \mathrm{day}^{-1}\right)$ for Mar (wet season) and Oct (dry season) 1999.

During the onset of rainy season in October, precipitation maxima occur over Colombia, Venezuela, and western Amazonas where the surface $K \downarrow$ and PAR $\downarrow$ fluxes show minima. However, radiation fields are not as highly inversely correlated with precipitation as in March because of the increase in aerosol smoke concentrations from biomass burning. For example, the local minima in $K \downarrow$ and PAR $\downarrow$ observed in the eastern parts of Pará and Peru and at the southwestern corner of the domain are not associated with precipitation maxima. These smaller fluxes are a consequence of biomass burning as seen from TOMS based on the monthly aerosol optical depth estimates shown in Fig. 5. The local maxima of $K \downarrow$ and PAR $\downarrow$ along the large rivers seen in March are still evident in October.

The flux pattern of $L \downarrow$ is largely determined by nearsurface air temperature, cloud amount, and the air temperature at cloud base. In March, the maximum downward infrared radiation is observed along the equator because of the fact that the sun is almost directly above the equator and therefore air masses in the vicinity of the equator undergo the greatest solar heating. As the sun migrates south in October, the $L \downarrow$ maximum is located in the southern part of the domain. The effect of cloudiness on $L \downarrow$ is manifest in the larger fluxes during the wet season relative to the dry season. Lowest fluxes are found in the southwestern corner of the domain where the air temperatures are lower because of the higher elevations.

\section{b. Daily variability}

The daily variations of area-averaged radiation and precipitation over rain forest and pasture areas [as identified from the land cover map of Loveland et al. (2000)] are shown in Fig. 6. Day-to-day variations of $K \downarrow$, PAR $\downarrow$, and RR are much larger than those associated with $L \downarrow$. Domainwide, there is little difference in daily variability between the wet and dry seasons with the exception of $L \downarrow$ fluxes. The $K \downarrow$ and PAR $\downarrow$ fluxes are greater in Oc- 


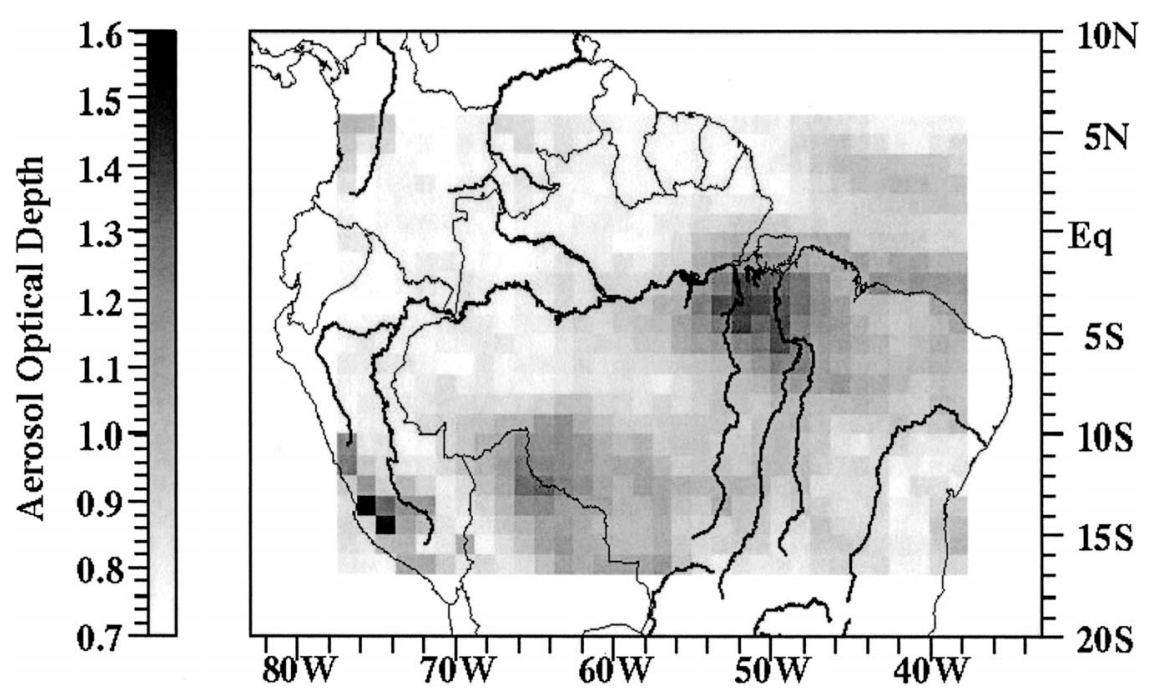

FIG. 5. Average aerosol optical depth at $0.38 \mu \mathrm{m}$ for Oct 1999. Optical depth is based on daily aerosol index derived from TOMS measurements and Eq. (1) discussed in text.

tober than in March because of reduced cloudiness and rainfall. In March, there are few differences in the $K \downarrow$ and PAR $\downarrow$ fluxes insofar as rain forest and pasture regions; in October, $K \downarrow$ and PAR $\downarrow$ fluxes within pasture regions are considerably smaller than within rain-forest regions. The lower fluxes over pasture regions during the dry season are due to the higher aerosol optical depths over mostly pasture and deforested areas in eastern Pará and Rondônia-as evident in Fig. 5.

Day-to-day variations in the $L \downarrow$ fluxes are small, more so in the wet season than in the dry season because of more uniform humidity conditions during the wet season. Also, fluxes are largest during the wet season because of greater cloud cover, also explaining why rain forest exhibits larger fluxes than pasture; that is, rain forest exhibits the highest cloud amounts.

As expected, the variations in daily rainfall found in Fig. 6 are in strong inverse correlation with $K \downarrow$ and PAR $\downarrow$ for either rain-forest or pasture regions, although these regions do not necessarily experience rainfall variations in phase with one another. In general, there are not large differences in rainfall between the rain-forest and pasture regions, although in the latter 10 days of March (wet season), the rain forest experiences approximately one-third more rainfall than the pasture regions.

\section{c. Diurnal variability}

Monthly composites of the diurnal variation of surface radiation and precipitation over rain-forest and pasture regions are illustrated in Fig. 7. As expected, $K \downarrow$ and PAR $\downarrow$ fluxes follow the diurnal cycle of solar zenith angle. However, there is a slight time shift between the rain-forest and pasture regions that is due to the fact that most of the rain-forest areas are located in the west- ern part of the study area while much of the pasture areas are to the east. The larger $K \downarrow$ and PAR $\downarrow$ fluxes in October are due to reduced rainfall and cloudiness; the even higher $K \downarrow$ and PAR $\downarrow$ fluxes over the rain-forest regions in that same month and in contrast to March are due to the greater smoke concentrations in deforested areas - as noted in the discussion of Fig. 6.

For both wet and dry seasons, the minimum diurnal $L \downarrow$ flux occurs around 1000 UTC or before sunrise for most of the domain, and the maximum $L \downarrow$ flux occurs around $1800 \mathrm{UTC}$, or some $2 \mathrm{~h}$ behind the maximum $K \downarrow$ near 1600 UTC (solar noon). The over $20 \mathrm{~W} \mathrm{~m}^{-2}$ difference in the rain-forest and pasture flux cycles is due to differences in cloud and precipitation factors discussed in the previous section.

For the wet season, the RR minimum is before sunrise, and the RR maximum is near sunset, associated with the late-afternoon buildup of convection lagging the maximum diurnal surface temperatures (not shown) by a few hours. These results are somewhat consistent with another Amazon rainfall study by Negri et al. (2002), which used a combined infrared-microwave satellite retrieval technique to obtain information on the diurnal cycle, albeit, over a subset of the region we analyzed. However, their study indicates the late-afternoon rainfall maximum to be over 3 times that of the morning minimum-whereas our results indicates this factor to be just above 2. The difference is likely due to the greater susceptibility of infrared-only satellite daytime measurements to overestimate rainfall in the presence of cirrus clouds, suggesting that a greater-than3 amplitude factor is too large. During the dry season, the RR minimum takes place at about the same time as the wet season, whereas the time of the maximum is earlier by almost $2 \mathrm{~h}$ because of the greater surface heating rates that occur under drier conditions. 

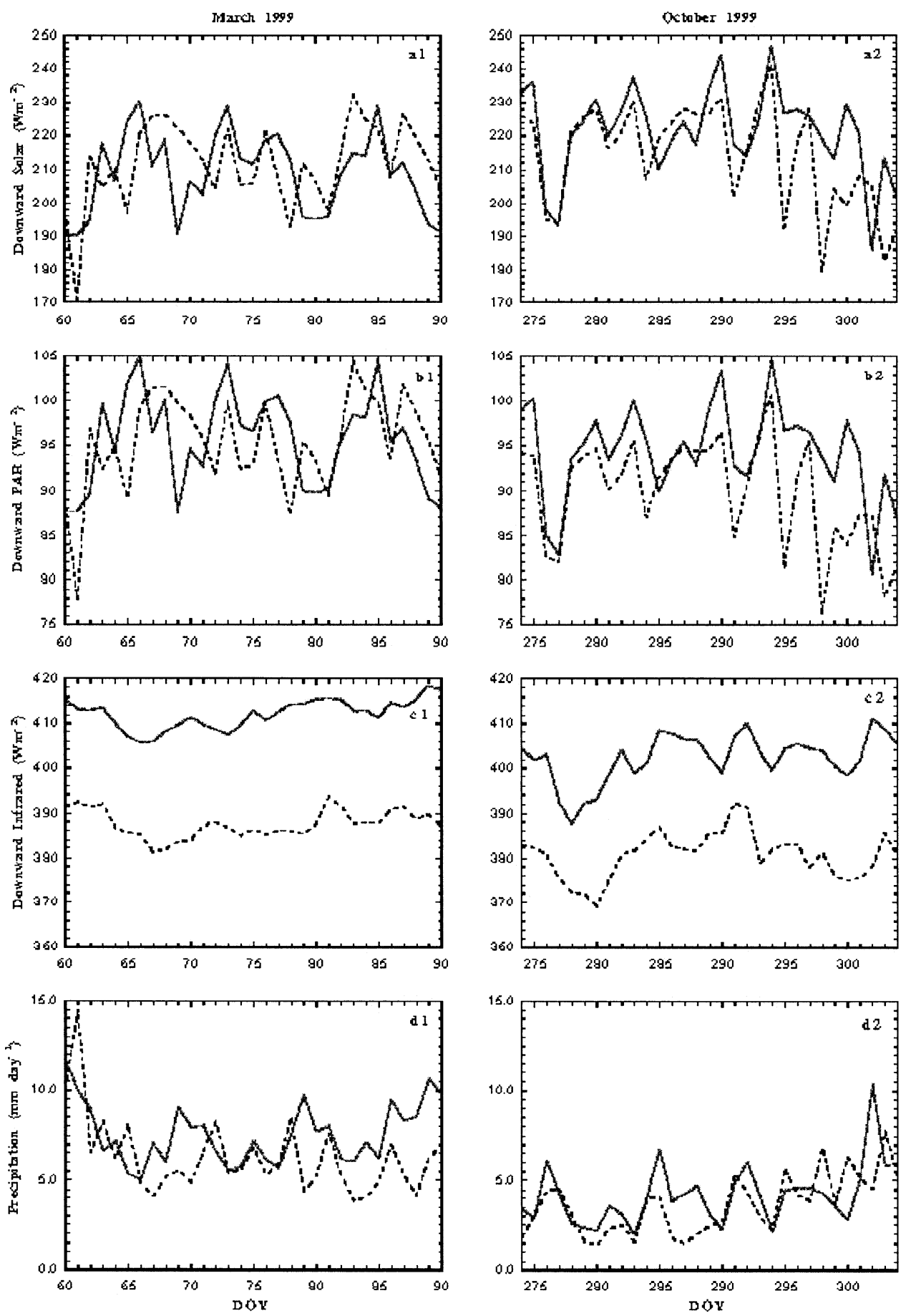

FIG. 6. Daily and domain-averaged incoming radiation and precipitation over rain forest (solid line) and pasture (dashed line) regions for Mar and Oct 1999: (a1), (a2) incoming total solar radiation flux in Mar and Oct, respectively; (b1), (b2) incoming PAR flux; (c1), (c2) incoming infrared radiation flux; and (d1), (d2) precipitation.

\section{Discussion and conclusions}

The retrievals of incoming surface solar radiation, PAR, and infrared radiation fluxes from GOES measurements over the large-scale Amazônia region, using existing algorithms tailored for applications in a tropical forest environment, indicate relatively close agreement with respect to validation-quality in situ measurements. Although the retrieved rain rates do not show the same 

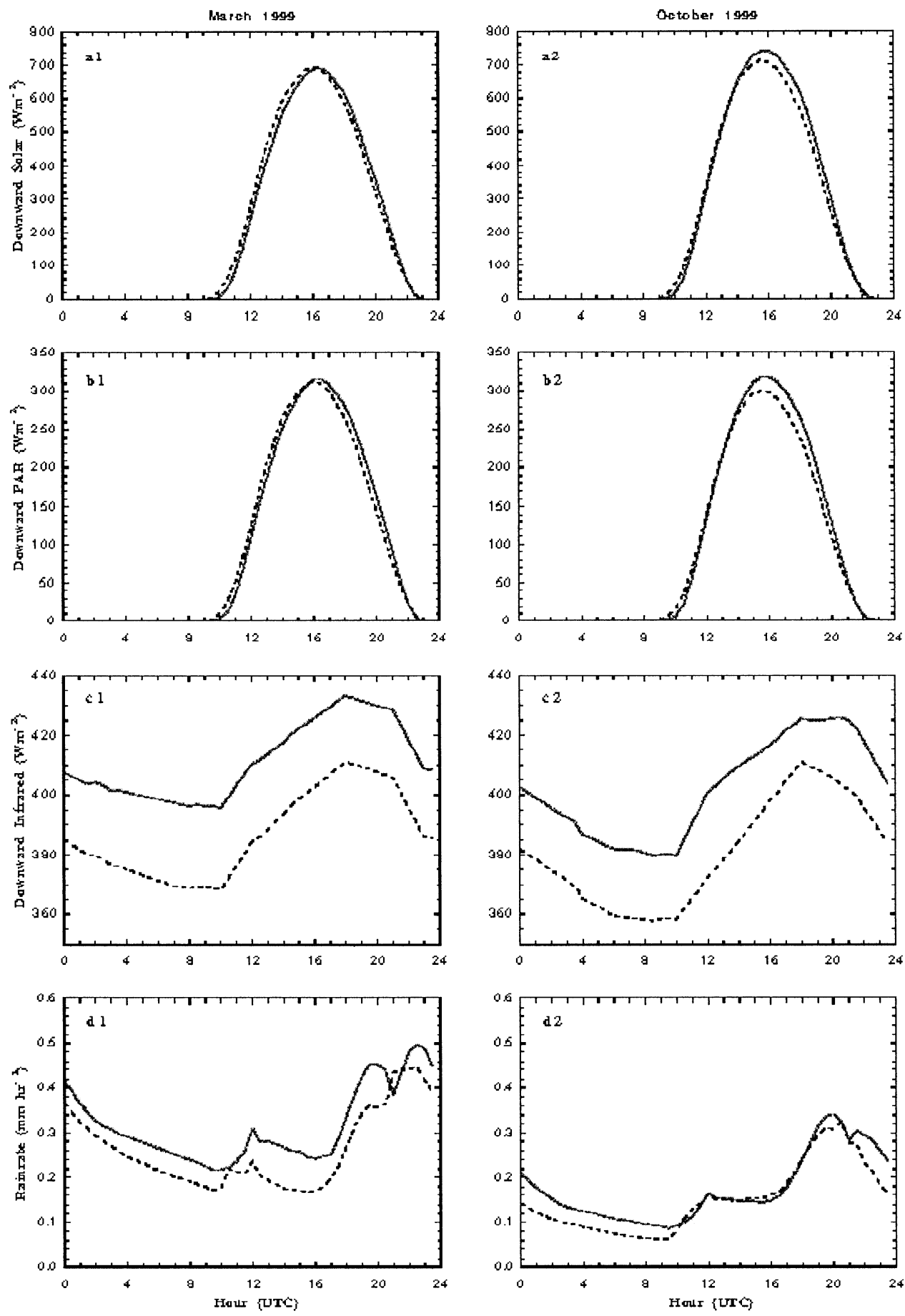

FIG. 7. Monthly and area-averaged diurnal variation of radiation and precipitation over rain forest (solid line) and pasture (dashed line) regions for Mar and Oct 1999. Panel arrangement is the same as in Fig. 6.

quality of validation, the systematic errors found in the validations with respect to the gauge data are within the expected level of uncertainty of $25 \%$.

The SRB algorithms were validated using in situ measurements collected in April and September of 1999 at the three EUSTACH-LBA sites. The correlation coef- ficients between satellite-retrieved and in situ measured incoming total solar radiation and PAR fluxes are approximately 0.92 and 0.95 for wet and dry seasons, respectively. The correlation for incoming infrared radiation is much less, around 0.5. However, ambient variations in $L \downarrow$ fluxes are much smaller relative to solar 
radiation fluxes, and thus a correlation estimate for hightime-resolution infrared radiation fluxes is much more sensitive to spurious variations in either the observed or retrieved fluxes. By the same token, bias errors for retrieved incoming total solar radiation, PAR, and infrared radiation fluxes at each site are under 4\%, 3\%, and $3 \%$ of the mean in situ measured values, respectively. The relative precision of incoming total solar radiation and PAR retrievals ranges from $17 \%$ to $25 \%$ of the means, whereas the relative precision of incoming infrared radiation is considerably less, some 3\%-7\% of the means. Note the cause of the tight agreement for the infrared fluxes is not unlike the cause of the lower correlation, that being the relatively small natural variation of $L \downarrow$ in a moist environment.

The performance of the rain-rate retrieval algorithm is less certain. Correlation coefficients for the four separate months between daily GOES and GPCP estimates within the grid box situated over the TRMM network range from 0.82 to 0.90 , which are large when compared with the corresponding coefficients between the daily gauge measurements and GPCP estimates, which range from 0.23 to 0.83 . Nonetheless, all bias errors (GOES vs GPCP or TRMM vs GPCP) are within the expected uncertainty of $25 \%$, which bodes well for carbon assimilation modeling. When directly comparing half-hourly GOES-pixel retrievals with TRMM observations, month by month and classified into daytime and nighttime categories, the correlation coefficients range from 0.2 to 0.4 , which highlights the ambiguities that arise in comparing point data with volume data.

The large-scale analysis indicates the strong influence of clouds, precipitation, and aerosols on the incoming total solar radiation and PAR fluxes and thus emphasizes the value that this kind of retrieval analysis can have on carbon budget modeling at the large scale. In March, the regions of minimum incoming total solar radiation and PAR fluxes are correlated well (in the inverse) with regions of maximum cloudiness and precipitation. In October, the incoming total solar radiation and PAR fluxes are highly modulated by both clouds and aerosols.

Incoming infrared radiation fluxes are mostly determined by near-surface air temperature (heavily influenced by moisture conditions) along with cloud location and amount. In March, when the elevation of the sun is high, maximum incoming infrared radiation fluxes are found near the equator. As the sun moves to southern latitudes in October, maximum fluxes move to the southern part of the study area. The effect of clouds is most evident on incoming infrared radiation fluxes in terms of the 10-20 $\mathrm{W} \mathrm{m}^{-1}$ differences between March and October, where the greater wet-season cloudiness produces the largest incoming infrared fluxes.

In terms of our modeling application, the two most important areas in which algorithm performance could stand improvement are cloud absorption and high-resolution precipitation retrieval. Cloud absorption of solar radiation is a topic for which there is disagreement among observationalists, modelers, and theoreticians as to whether current models correctly simulate the physics and the degree to which solar energy is absorbed in a cloudy environment ( $\mathrm{Li}$ et al. 1995; Valero et al. 1997; Collins 1998). It is known that cloud absorption is determined by a large set of variables from direction and wavelength of the incident radiation to the phase, shape, size, concentration, and liquid/ice water contents of cloud hydrometeors-as well as important boundary condition effects such as surface albedo. Our current treatment of cloud absorption as a function of cloud visible albedo is a first-order approximation but is also practical in the sense that information concerning detailed cloud microphysics that would warrant a more physically explicit algorithm is not readily available. One possible means to overcome this lack would be some kind of stochastic ensemble treatment of cloud microphysical properties. However, until more is known about cloud microphysics within the Amazon, this subject remains challenging.

There is room for improvement in rain-rate retrieval from GOES observations, particularly over short space and time scales (e.g., North et al. 1994; Sheu et al. 1996). GOES visible reflectances and infrared EBBTs are determined by macroscale cloud characteristics near cloud top, properties not directly associated with surface rainfall intensity. Nevertheless, there is great value in such retrievals because the frequency of geostationary satellite observations is so much higher than those of low earth orbiters carrying more accurate passive microwave sensors and/or precipitation radars. It is important that when considering GOES observations as the sole source of rainfall data, the accuracy of the GOES retrievals can be made to depend on the accuracies inherent to microwave retrievals such as developed for SSM/I and TRMM observations. In fact, over the Amazon, where there currently are no weather radars capable of providing research-quality precipitation measurements, combining frequent observations from GOES with more accurate but less frequent observations from SSM/I and TRMM serves as an effective rainfall data source (Adler et al. 1994; Bellerby et al. 2000; Negri et al. 2002).

Future improvement of GOES-based precipitation retrievals could be accomplished by developing a supervised classification algorithm based on research-quality precipitation radar measurements made in the Amazon over the long term. However, high-quality radars such as the System for Vigilance over the Amazon (SIVAM) now planned for deployment in the Amazon have yet to produce the needed precipitation time series (C. Nobre 2002, personal communication). With an appropriate radar-based cloud classification scheme, such an algorithm could be designed to distinguish between convective and stratiform rainfall. Rain-onset thresholds and coefficients for rain-rate conversion could then be selected according to rain type. This approach would reduce retrieval errors, because convective and strati- 
form clouds generally have significant differences in precipitation intensities.

Another approach would be a supervised classification procedure based on precipitation estimates from the TRMM Microwave Imager and TRMM precipitation radar. Unlike visible and infrared radiances, radar reflectivities and passive microwave brightness temperatures are physically related to rainfall so that such estimates could be used to train GOES visible and infrared algorithms whenever coincident observations are available. However, as noted, the current bias uncertainties of TRMM retrievals are on the order of $25 \%$, and so until TRMM precipitation algorithms are better refined this approach must be held in abeyance.

Acknowledgments. The authors express their appreciation to Dr. Brent Holben and his AERONET team for providing aerosol optical depth measurements and to Dr. Richard McPeters and other TOMS investigators for providing their aerosol index product. We also thank Messrs. Brad Fisher and Jianxin Wang for providing TRMM ground validation data and Drs. Alan Betts and John Ball for their helpful advice on processing it. This research has been supported by NASA LBA Grant NCC5292.

\section{REFERENCES}

Adler, R. F., G. J. Huffman, and P. R. Keehn, 1994: Global tropical rain estimates from microwave-adjusted geosynchronous IR data. Remote Sens. Rev., 11, 125-152.

Andreae, M. O., and Coauthors, 2002: Biogeochemical cycling of carbon, water, energy, trace gases and aerosols in Amazonia: The LBA-EUSTACH experiments. J. Geophys. Res., 107, 8066, doi:10.1029/2001JD000524.

Araújo, A. C., and Coauthors, 2002: Comparative measurements of carbon dioxide fluxes from two nearby towers in a central Amazonian rainforest: The Manaus LBA site. J. Geophys. Res., 107, 8090, doi:10.1029/2001JD000676.

Arkin, P. A., and P. Xie, 1994: The Global Precipitation Climatology Project: First Algorithm Intercomparison Project. Bull. Amer. Meteor. Soc., 75, 401-419.

Bastable, H. G., W. J. Shuttleworth, R. L. G. Dallarosa, G. Fisch, and C. A. Nobre, 1993: Observations of climate, albedo and surface radiation over cleared and undisturbed Amazonian forest. Int. J. Climatol., 13, 783-796.

Bellerby, T., M. Todd, D. Kniveton, and C. Kidd, 2000: Rainfall estimation from a combination of TRMM precipitation radar and GOES multispectral imagery through the use of an artificial neural network. J. Appl. Meteor., 39, 2115-2128.

Bonan, G. B., 1996: A land surface model for ecological, hydrological and atmospheric studies. NCAR Tech. Note NCAR/TN$417+$ STR, National Center for Atmospheric Research, Boulder, $\mathrm{CO}, 150 \mathrm{pp}$.

Chahine, M. T., 1992: GEWEX: The Global Energy and Water Cycle Experiment. Eos, Trans. Amer. Geophys. Union, 73, 13-14.

Collins, W. D., 1998: A global signature of enhanced shortwave absorption by clouds. J. Geophys. Res., 103, 31 669-31679.

Cooper, H., E. A. Smith, and M. Rubes, 1998: Relevance of surface energy budget within Florida sea-breeze front to cross-peninsula rainwater runoff gradient. J. Appl. Meteor., 37, 939-950.

Diak, G. R., and C. Gautier, 1983: Improvements to a simple physical model for estimating insolation from GOES data. J. Climate Appl. Meteor., 22, 505-508.
Fan, S.-M., S. C. Wofsy, P. S. Bakwin, D. J. Jacob, and D. R. Fitzjarrald, 1990: Atmosphere-biosphere exchange of $\mathrm{CO}_{2}$ and $\mathrm{O}_{3}$ in the central Amazon forest. J. Geophys. Res., 95, $16851-$ 16864 .

Frouin, R., D. W. Lingner, C. Gautier, K. S. Baker, and R. C. Smith, 1989: A simple analytical formula to compute clear sky total and photosynthetically available solar irradiance at the ocean surface. J. Geophys. Res., 94, 9731-9742.

Gash, J. H. C., C. A. Nobre, J. M. Roberts, and R. L. Victoria, 1996: An overview of ABRACOS. Amazonian Deforestation and Climate, J. H. C. Gash et al., Eds., John Wiley and Sons, 1-14.

Gautier, C., and M. Landsfeld, 1997: Surface solar radiation flux and cloud radiative forcing for the Atmospheric Radiation Measurement (ARM) Southern Great Plains (SGP): A satellite, surface observations, and radiative transfer model study. J. Atmos. Sci., 54, 1289-1307.

— - G. Diak, and S. Masse, 1980: A simple physical model to estimate incident solar radiation at the surface from GOES satellite data. J. Appl. Meteor., 19, 1005-1012.

Grace, J., and Coauthors, 1995: Carbon dioxide uptake by an undisturbed tropical rain forest in southwest Amazonia, 1992 to 1993. Science, 270, 778-780.

Greco, S., and Coauthors, 1990: Rainfall and surface kinematic conditions over central Amazonia during ABLE 2B. J. Geophys. Res., 95, 17 001-17 014.

Gu, J., and E. A. Smith, 1997: High resolution estimates of total solar and PAR surface fluxes over large scale BOREAS study area from GOES measurements. J. Geophys. Res., 102, 29 685-29 705.

, ——, G. Hodges, and H. J. Cooper, 1997: Retrieval of daytime surface net longwave flux over BOREAS from GOES estimates of surface solar flux and surface temperature. Can. J. Remote Sens., 23, 176-187.

_,$\ldots$, and J. D. Merritt, 1999: Testing energy balance closure with GOES-retrieved net radiation and in situ measured eddy correlation fluxes in BOREAS. J. Geophys. Res., 104, 27 88127893.

Haxeltine, A., and I. C. Prentice, 1996: A general reference for the light-use efficiency of primary production. Funct. Ecol., 10, 551561.

Herman, J. R., P. K. Bhartia, O. Torres, C. Hsu, C. Seftor, and E. Celarier, 1997: Global distribution of UV absorbing aerosol from Nimbus 7 TOMS data. J. Geophys. Res., 102, $16911-16922$.

Holben, B. N., and Coauthors, 1998: AERONET-A federated instrument network and data archive for aerosol characterization. Remote Sens. Environ., 66, 1-16.

Hsu, N. C., and Coauthors, 1999: Comparisons of the TOMS aerosol index with sun-photometer aerosol optical thickness: Results and applications. J. Geophys. Res., 104, 6269-6279.

Huffman, G. J., 1997: Estimates of root-mean-square random error for finite samples of estimated precipitation. J. Appl. Meteor., 36, 1191-1201.

— , and Coauthors, 1997: The Global Precipitation Climatology Project (GPCP) combined precipitation dataset. Bull. Amer. Meteor. Soc., 78, 5-20.

_, R. F. Adler, M. Morrissey, D. T. Bolvin, S. Curtis, R. Joyce, B. McGavock, and J. Susskind, 2001: Global precipitation at one-degree daily resolution from multisatellite observations. $J$. Hydrometeor., 2, 36-50.

Kalnay, E., and Coauthors, 1996: The NCEP/NCAR 40-Year Reanalysis Project. Bull. Amer. Meteor. Soc., 77, 437-471.

Kaufman, Y. J., and T. Nakajima, 1993: Effect of Amazon smoke on cloud microphysics and albedo-Analysis from satellite imagery. J. Appl. Meteor., 32, 729-744.

King, P. W. S., W. D. Hogg, and P. A. Arkin, 1995: The role of visible data in improving satellite rain-rate estimates. J. Appl. Meteor., 34, 1608-1621.

Knapp, K. R., and T. H. Vonder Haar, 2000: Calibration of the Eighth Geostationary Observational Environmental Satellite (GOES-8) imager visible sensor. J. Atmos. Oceanic Technol., 17, 16391644. 
Kummerow, C., and Coauthors, 2000: The status of the Tropical Rainfall Measuring Mission (TRMM) after two years in orbit. J. Appl. Meteor., 39, 1965-1982.

Lawford, R. G., 1999: A midterm report on the GEWEX ContinentalScale International Project (GCIP). J. Geophys. Res., 104, 19 27919292.

Li, Z., H. W. Barker, and L. Moreau, 1995: The variable effect of clouds on atmospheric absorption of solar radiation. Nature, $\mathbf{3 7 6}$, 486-490.

Liou, K. N., 1992: Radiation and Cloud Processes in the Atmosphere. Oxford University Press, $487 \mathrm{pp}$.

Loveland, T. R., B. C. Reed, J. F. Brown, D. O. Ohlen, J. Zhu, L. Yang, and J. W. Merchant, 2000: Development of a global land cover characteristics database and IGBP DISCover from 1-km AVHRR data. Int. J. Remote Sens., 21, 1303-1330.

Lubin, D., J. Chen, P. Pilewskie, V. Ramanathan, and F. P. J. Valero, 1996: Microphysical examination of excess cloud absorption in the tropical atmosphere. J. Geophys. Res., 101, 16 961-16972.

Meir, P., J. Grace, A. Miranda, and J. Lloyd, 1996: Soil respiration in a rainforest in Amazonia and in Cerrado in central Brazil. Amazonia Deforestation and Climate, J. H. C. Gash et al., Eds., John Wiley and Sons, 319-330.

Menzel, W. P., T. J. Schmit, and D. P. Wylie, 1990: Cloud characteristics over central Amazonia during GTE/ABLE 2B derived from multispectral visible and infrared spin scan radiometer atmospheric sounder observations. J. Geophys. Res., 95, 17039 17042.

Negri, A. J., E. N. Anagnostou, and R. F. Adler, 2000: A 10-yr climatology of Amazonian rainfall derived from passive microwave satellite observations. J. Appl. Meteor., 39, 42-56.

—_, L. Xu, and R. F. Adler, 2002: A TRMM-calibrated infrared rainfall algorithm applied over Brazil. J. Geophys. Res., 107, 8048, doi:10.1029/2000JD000265.

Norman, J. M., R. Garcia, and S. B. Verma, 1992: Soil surface $\mathrm{CO}_{2}$ fluxes and the carbon budget of a grassland. J. Geophys. Res., 97, 18 845-18 853 .
North, G. R., J. B. Valdes, E. Ha, and S. S. P. Shen, 1994: The groundtruth problem for satellite estimates of rain rate. J. Atmos. Oceanic Technol., 11, 1035-1041.

Rahman, A. F., J. A. Gamon, D. A. Fuentes, D. A. Roberts, and D. Prentiss, 2001: Modeling spatially distributed ecosystem flux of boreal forest using hyperspectral indices from AVIRIS imagery. J. Geophys. Res., 106, 33 579-33 591.

Rossow, W. B., and R. A. Schiffer, 1999: Advances in understanding clouds from ISCCP. Bull. Amer. Meteor. Soc., 80, 2261-2287.

Sheu, R.-S., J. A. Curry, and G. Liu, 1996: Satellite retrieval of tropical precipitation using combined ISCCP DX and microwave datasets. J. Geophys. Res., 101, 21 291-21 301.

Smith, E. A., and Coauthors, 1992: Area averaged surface fluxes and their time-space variability over the FIFE experimental domain. J. Geophys. Res., 97, 18 559-18 622.

Takle, E. S., and Coauthors, 1999: Project to Intercompare Regional Climate Simulations (PIRCS): Description and initial results. $J$. Geophys. Res., 104, 19 443-19 461.

Torres, O., P. K. Bhartia, J. R. Herman, Z. Ahmad, and J. Gleason, 1998: Derivation of aerosol properties from satellite measurements of backscattered ultraviolet radiation: Theoretical basis. J. Geophys. Res., 103, 17 099-17 110.

Valero, F. P. J., R. D. Cess, M. Zhang, S. K. Pope, A. Bucholtz, B. Bush, and J. Vitko Jr., 1997: Absorption of solar radiation by the cloudy atmosphere: Interpretations of collocated aircraft measurements. J. Geophys. Res., 102, 29 917-29 927.

Weinreb, M. P., M. Jamieson, N. Fulton, Y. Chen, J. X. Johnson, J. Bremer, C. Smith, and J. Baucom, 1997a: Operational calibration of the images and sounders on the GOES- 8 and GOES-9 satellites. NOAA Tech. Memo. NESDIS 44, National Environmental Satellite and Data Information Service, Camp Springs, MD, 32 pp. $-\longrightarrow,-,-,-\longrightarrow,-$, and,- 1997b: Operational calibration of Geostationary Operational Satellite- 8 and -9 imagers and sounders. Appl. Opt., 36, 6895-6904. 